To the Editors:

\title{
A study on suicide by self immolation
}

Ceylon Medical Journal 2011; 56: 182-183

Deaths from suicides reached a peak in Sri Lanka in 1995 to 48.7 per 100,000 population, the highest in the world. Several interventions reduced the rate to 20.6 per 100,000 in 2007 [1]. Self immolation (SI) as a method of suicide is reported from many developing countries [2,3]. In 2006, 3558 males and 946 females (total 4504) committed suicide in Sri Lanka. SI was the method used by 148 $(3.3 \%)-48$ males and 130 females.

We studied suicidal deaths from burns at the Coroner's Court, Colombo, for one year from 1st January 2006. The investigating police officer and close relations/ friends who attended the inquest held by an Inquirer into Sudden Deaths (ISD) were interviewed. There were 151 suicides - 93 men (62\%) and 58 women (38\%). 51 (34\%) suicides were due to SI. Age and sex of the victims are shown in Table 1. The female to male ratio was 3.3:1.

Table 1. Age and sex of the victims

\begin{tabular}{lccc}
\hline Age group & Male & Female & Total \\
\hline $0-19$ & 1 & 10 & 11 \\
$20-29$ & 3 & 13 & 16 \\
$30-39$ & 2 & 4 & 6 \\
$40-49$ & 5 & 5 & 10 \\
$50-59$ & 0 & 3 & 3 \\
$60-69$ & 1 & 1 & 2 \\
$70-79$ & 0 & 1 & 1 \\
$80-89$ & 0 & 1 & 1 \\
$>90$ & 0 & 1 & 1 \\
Total & 12 & 39 & 51 \\
\hline
\end{tabular}

Table 2. Level of education

\begin{tabular}{lcc}
\hline Level of education & Number & Percentage \\
\hline None & 7 & $13.7 \%$ \\
Year 1-5 & 8 & $15.7 \%$ \\
Year 6-11 & 23 & $45.1 \%$ \\
Year 12-13 & 6 & $11.8 \%$ \\
Degree or Higher & 1 & $2.0 \%$ \\
Not Known & 6 & $11.8 \%$ \\
Total & 51 & $100 \%$ \\
\hline
\end{tabular}

The level of education showed that $14 \%$ had no school education. $16 \%$ had school education up to year $5,45 \%$ up to grade $6-11$ and $12 \%$ up to year $13.32(63 \%)$ victims were married, $10(20 \%)$ were single, $5(10 \%)$ were widowed, $3(6 \%)$ were living together and one $(2 \%)$ was separated.

Table 3. Reasons for suicide

\begin{tabular}{lcc}
\hline Reason for suicide & Number & Percentage \\
\hline Psychosis & 2 & $4.0 \%$ \\
Alcohol dependence & 1 & $2.0 \%$ \\
Dispute with wife & 5 & $10.0 \%$ \\
Dispute with husband & 15 & $29.4 \%$ \\
Dispute with children & 1 & $2.0 \%$ \\
Dispute with parents & 5 & $10.0 \%$ \\
Dispute with brother/sister & 1 & $2.0 \%$ \\
Unemployment & 2 & $4.0 \%$ \\
Financial reasons & 3 & $5.9 \%$ \\
Grief reaction & 1 & $2.0 \%$ \\
Marital unhappiness & 3 & $5.9 \%$ \\
Organic disease & 2 & $4.0 \%$ \\
No clear reason & 8 & $15.7 \%$ \\
'Broken' love affair & 2 & $4.0 \%$ \\
Total & 51 & $100 \%$ \\
\hline
\end{tabular}

The living circumstances of the victims showed that $42(82 \%)$ were living with their families (including a partner) while $8 \%$ were living alone. five lived with friends or others. In $36(71 \%)$ cases SI took place inside their own residence. One committed suicide in a boarding house and 14 in other private places. Although 33\% of the victims were unemployed, it was the reason to commit suicide only in $2 \%$. There were 6 skilled and 5 unskilled workers, 4 sales workers and one each of supervisors, technical workers and clerical workers. The commonest reason for suicide (45\%) was dispute with the spouse/ marital disharmony (Table 3). In this study nearly 53\% of the victims were below 30 years and $76 \%$ were females highlighting the fact that SI is common among young females. 


\section{Acknowledgements}

The authors thank Wellcome Trust/National Health and Medical Research Council International Collaborative Research Grant 071669MA for financial assistance.

\section{References}

1. Gunnell D, Fernando R, Hewagama M, Priyangika WD, Konradsen F, Eddleston M. The impact of pesticide regulations on suicide in Sri Lanka. International Journal of Epidemiology 2007; 36: 1235-42.

2. Laloe V, Ganesan M. Self-immolation a common suicidal behaviour in eastern Sri Lanka. Burns 2002; 28: 475-80.

3. Ahmadi A. Suicide by self-immolation: comprehensive overview, experiences and suggestions. Journal of Burn Care Research 2007; 28: 30-41.

4. Sri Lanka Police. http://www.police.lk/divisions/crime/ mode_of_suicide_2006.htm: 2006.

\section{R Fernando ${ }^{1}$, M Hewagama $^{1}$, W D Priyangika ${ }^{1}$, S Range $^{1}$, S Karunaratne $^{1}$}

${ }^{1}$ Department of Forensic Medicine and Toxicology, Faculty of Medicine, University of Colombo, Sri Lanka.

Correspondence: RF, e-mail: <ravindrafernando@hotmail.co.uk>. Received 26 October 2010 and revised version accepted 6 April 2011. Competing interests: none declared. 